
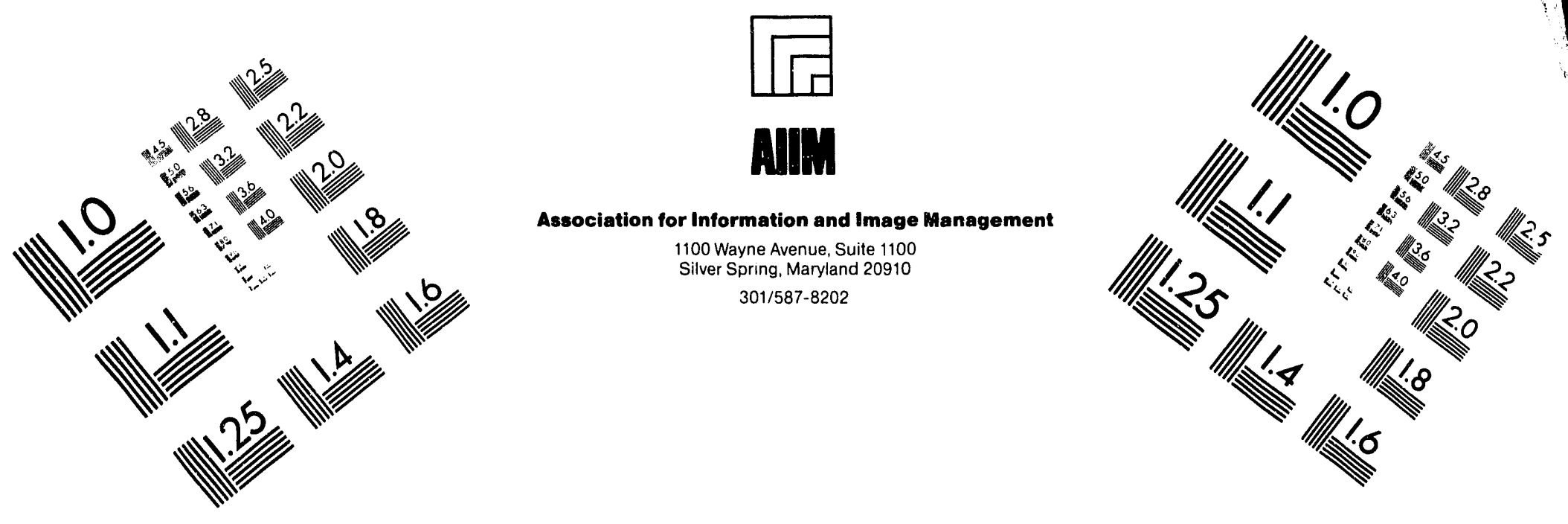

Centimeter

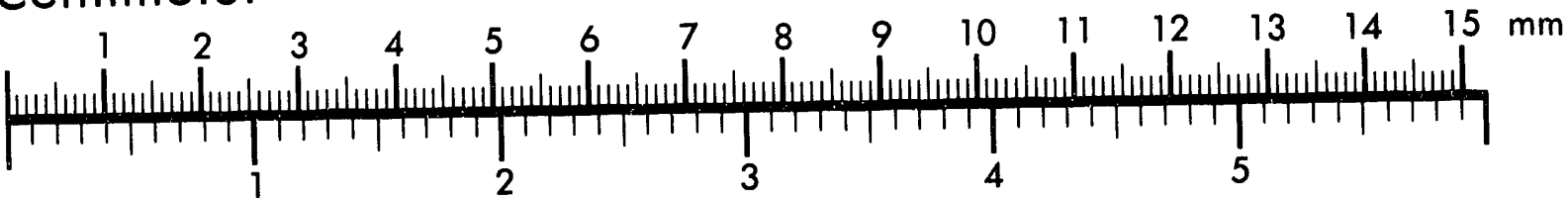
Inches
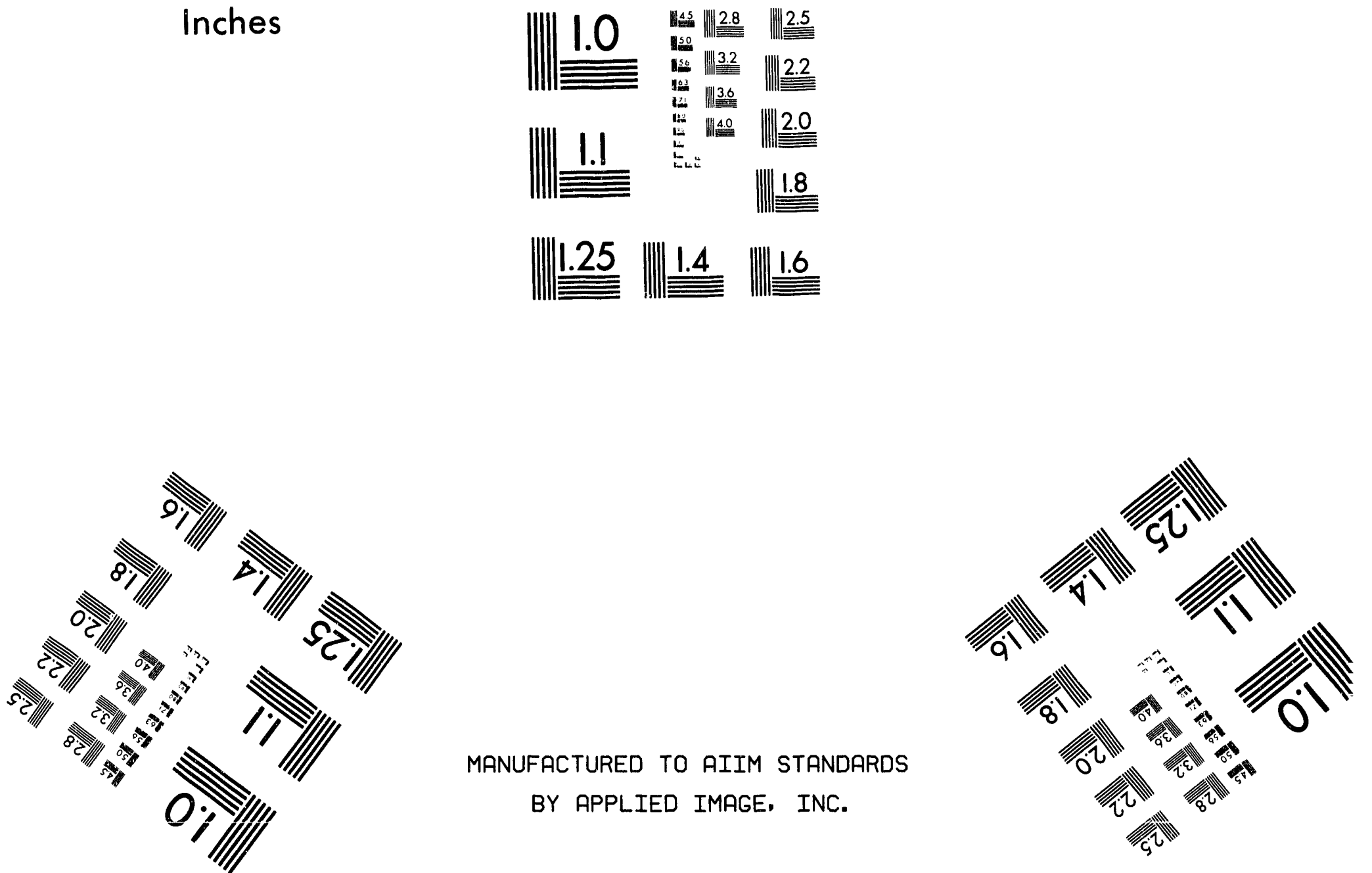

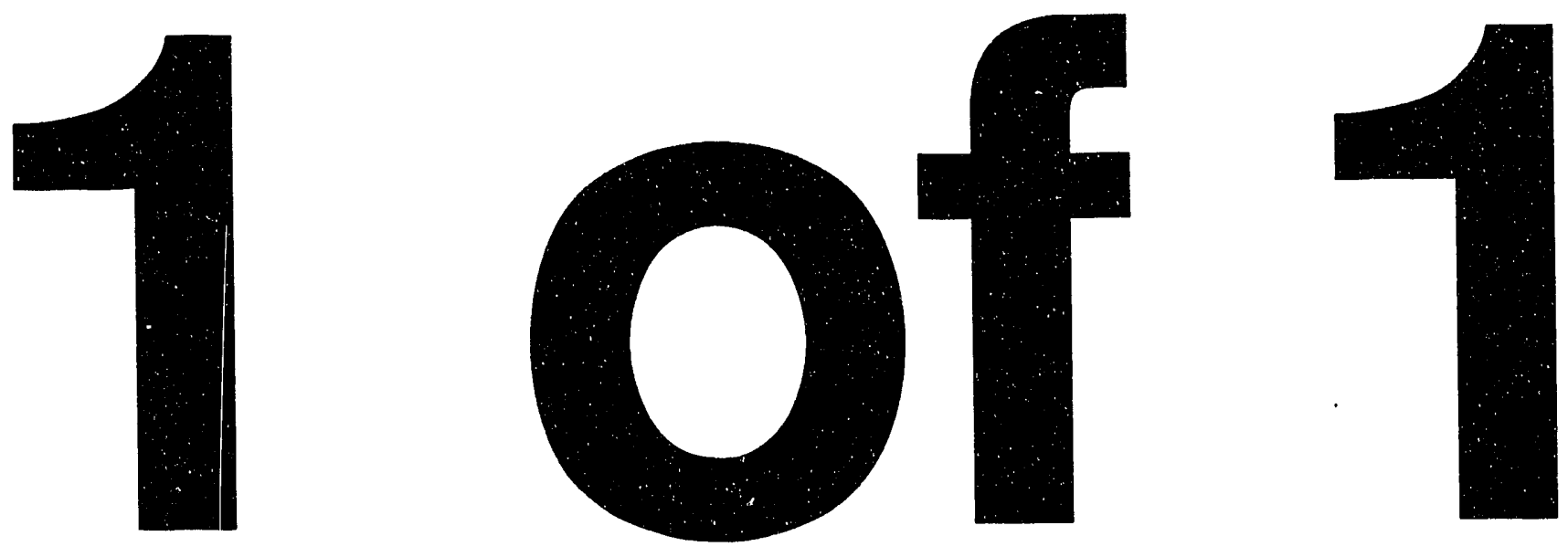


\title{
In Situ Electrochemical Characterization of Grouted Radioactive Waste
}

\author{
A. A. Kruger \\ Date Published \\ April 1993
}

To Be Presented at

1993 International Conference on Nuclear Waste

Management and Environmental Remediation

Prague Czech Republic

Seplember 5-11, 1993

Prepared for the U.S. Department of Energy

Environmental Restoration and

Waste Management

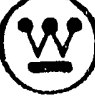

Westinghouse

P.O. Box 1970

Hanford Company Richland, Washington 99352

IIanford Operafions and Engineering Contractor for the

U.S. Dopnitinent of Energy under Contract DE AC06 $87 \mathrm{RL} 10930$

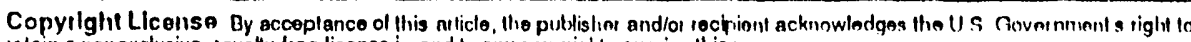

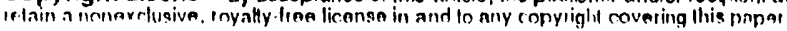

Approved for Public Release

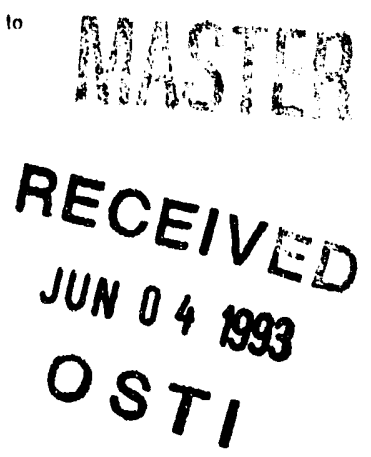




\section{LEGAL DISCLAIMER}

This report was prepared as an account of work sponsored by an agency of the United States Government. Neither the United States Government nor any agency thereol, nor any of their employees, nor any of their contractors, subcontractors or their employees, makes any warranty, express or implied. or assumes any legal liability or responsibility for the accuracy, completeness, or any third party's use or the results of such use of any information, apparatus, product, or process disclosed, or represents that its use would not intringe privately owned rights. Reference herein to any specific commercial product, process, or service by trade name, trademark, manulacturer, or otherwise, does not necessarily constitute or imply its endorsement, recommendation, or lavoring by the United States Government or any agency there or its contractors or subcontractors. The views and opinions of authors expressed herein do not necessarily state or reflect those of the United States Government or any agency thereo!

This report has been reproduced from the best available copy Available in paper copy and microfiche.

Available to the U.S. Department of Energy

and its contractors from

Office of Scientific and Technical Information

D.O. Box 62

Oak Ridge, TN 37831

(615) $576-840$

Printed in the United States ol America

DISCLM-3 CHP (1.91) 
WHC-SA-1630-FP

\title{
In Situ Electrochemical Characterization of Grouted Radioactive Waste
}

\author{
Jingyan Gu, Wu-Mian Shen and Micha Tomklewicz \\ Department of Physics \\ Brooklyn College of CUNY \\ Brooklyn, New York
}

\author{
Albert A. Kruger \\ Westinghouse Hanford Company \\ MSIN R4-03 \\ Richland, Washington
}

\begin{abstract}
At the Hanford Site, twenty-eight double-shell lanks (DST) and one hundred and forty nine single-shell tanks (SST) are used for storage of radioactive liquid and sludge wastes and salt cake. $A$ fundamental goal of the Westinghouse Hanford Company is to end the current storage practice for liquid wastes and to permanently dispose of the waste. The Hanford Defense Waste Environmental Impact Statement and subsequent record of decision has identified a cement-based waste form for disposal of DST low-level liquid waste.

The low level radioactive fractions of these wastes will be immobilized in a cementitious grout at the Hanford Grout Processing Facility and disposed of in concrete vaults of the Grout Disposal Facility. Prior to closing each vault, postcuring verification will show that the final product meets the performance requirements. Any long term disposal system of radioactive waste will require monitoring to warn against structural deterioration and/or leach of the radioactive or hazardous components into the environment.

We are investigating the possibility of monitoring the degree of immobilization of the waste by embedding a grid of long-lasting electrodes in grout. This work describes our ongoing attempts to understand the physics and chemistry of charge carriers in the grout under various load conditions.
\end{abstract}

\section{Introduction}

The properties of composites and porous materials are a subject of increasing importance and in one form or another a review on the subject appears on an annual basis 1 . Their utility in electrochemical systems and in particular in battery and fuel cell applications, is widespread. It was realized that the lifetime of cement-based materials is to a large degree determined by the supply and transport of ionic species? 2 . The electrochemistry of cement-based materials started to be of prime interest because of the corrosion problems of reinforced concrete and its effects on the global infrastructure ${ }^{3}$. Computer simulation of conductance in a simulated cement was reported by Garboczi et al. 4 and impedance measurements by Christensen et al. 5 .

The simplest correlation between the electrical conductivity of a porous insulator flooded with a conducting electrolyte is given by

$$
\sigma_{r}=\sigma_{W} / F \approx \sigma_{W} \phi^{m}
$$

where $\sigma_{r}$ - conductivity of sample, $\sigma_{w}$ - conductivity of the electrolyte, $\phi$ is the porosity of the sample and $F$ is a geometrical formation factor and $m$ is an exponent defined by this equation. This relationship is known as Archie's law ${ }^{6}$ and arguably is responsible for a significant fraction of the earning of the oil logging industry. For multielectrolyte composition the ionic conductivity is the sum of the contributions of the individual ions given by:

$$
\sigma=F \sum_{j=1}^{1} u_{j j} C_{j}
$$


where $z$ is the ionic charge, $\mu$ its mobility, and $C$ the ionic concentration.

The objective of any electrochemical probe is to be able to monitor the individual ionic mobilities and concentrations and the structural parameters such as the porosity and the structural formation factor. There is no single probe that can accomplish such a task. A multitude of probes are needed. The obiective of our program is to test any possible electrochemical technique for its applicability to monitor the static and dynamic processes that take place in the grout and by doing so learn as much as we can about the electrochemistry of cement-based materials. Here we report on our preliminary findings that will include electrode configurations, impedance measurements and rest potentials.

\section{Sample Preparations}

We report here results on two types of grouts: Portland Cement (II) and the composite that is being presently used at the Hanford site with the following composition: Portland Cement (I/II) $20.7 \%$, Fly Ash $68.3 \%$ and Clay $10.95 \%$. The three powders in the composite were mixed for $48 \mathrm{hrs}$ in a V-Blender, then mixed with the appropriate electrolytes in a mixer for $15 \mathrm{~min}$. to form a consistent paste. Stainless steel wires of $0.024^{\prime \prime}$ diameter or chicken wire were used as electrodes. Typical setting conditions include covering the cement paste with the electrolyte in a sealed container for $24 \mathrm{hrs}$ at room temperature. Other setting conditions will be described in conjunction with the various experiments.

\section{Electrode Configurations}

One of the main attractions of the electrochemical probing techniques is that the hardware needed to carry out most of the conceivable measurements can be installed before or parallel to the development of the basic understanding of these systems and hence the development of an exact protocol for measurements. The basic unit that will be used is based on four probes in an arrartgement similar to the one shown in Figure 1. The electrode material of choice at present is the stainless steel type 304V.

\section{Impedance}

Broad frequency range impedance measurements offer the advantage of direct, in situ, correlation between the morphology and the electrochemical dynamics of such systems. The desired outcome of such an experiment is the correlation, through the morphology of the system, of the macroscopic frequency dispersion of the real and imaginary parts of the impedance with the microscopic charge accumulation and transport modes at the interface 4 . This technique also offers the possibility of nondestructive tomography?.

\section{Electrode configuration}

Any attempt to measure the dielectric properties of a bulk material should include a procedure that eliminates the contributions of the contacts. The four-probe method is regarded as the best procedure to accomplish it. It is widely being used to measure the resistance of semiconductors and superconductors and was published as a standard to measure resistivity of soil samples ${ }^{8}$. Alternative procedure is to use the fact that the contact impedance is distance independent while the bulk impedance should scale linearly with the length. Most of the work in the literature on similar systems is concerns with these problems only for DC measurements while the $A C$ measurements are done in two electrode configurations. Figure 2 shows the impedance spectrum of type II Portland cement mixed with $1 \mathrm{M} \mathrm{NaNO}_{3}$ electrolyte $(\mathrm{W} / \mathrm{C}=1: 2)$ using two-wire electrode configuration. Four electrodes were placed with equal separation in a straight line in the cementitious grouts. An applied voltage of the generator was imposed between the outer electrodes, and the voltage drop between the inner electrodes was measured. The current flowing through sample was measured through the voltage drop across a series resistor with a known resistance.

Figure 3 shows the impedance spectrum of the cementitious grout identical to the one used to produce Figure 2, but with the four-probe electrode arrangement. It is obvious that the polarization effect was nearly totally excluded from the real components of the measured impedances. The imaginary component poses a series problem here because of the small bulk capacitance involved (around 10pf). Our experimental setup for impedance measurements was described before ${ }^{9}$. It is based on the Solatron 1250 and the Hewlett-Packard (HP) network analyzer .

For the Solatron 1250 Frequency Response Analyzer, one gets the maximum accuracy by grounding the lower terminals of the generator and the two analyzers. Four-probe technique requires that at least the lower terminal of one analyzer will not be grounded. This may induce some noise pickup. Since the lower terminals of the analyzers must be 
grounded for the HP impedance measuring system, it can not be used for the four-probe measurement system. Therefore, four-probe system can be measured with the Solatron 1250 only if an upper frequency limit of $65 \mathrm{kHz}$ is imposed. In order to extend the measuring frequencies up to $10 \mathrm{MHz}$ (HP system), and keep the lower terminals of the analyzers grounded, a three-probe system was developed and tested. In this arrangement, the applied voltage of the generator was imposed between the two outer electrodes, of the four aligned, to keep the current that passes through the cement constant. The impedance between each of the inner electrodes and the outer electrode with the lower potential is measured. The difference between the two impedances is the impedance between the inner electrodes. The effects of polarization, lead wire impedance, and the inductive coupling are all excluded since all of those items are independent of the interelectrode spacing ${ }^{10}$, and cancel by taking the difference between the above two impedance measurements. A typical impedance spectrum is shown in Figure 4 . The real component of impedance from the two three-probe measurements is almost identical with that of the four-probe measurements over the frequency range in which the modes can apply (compare with Figure 4.) The imaginary component of the impedance exhibits a smooth spectrum with less noisy scatter and better Nyquist plot.

\section{Time evolution}

We have used the three electrode configuration to evaluate the time evolution of the impedance of five samples of the composite grout with different $\mathrm{NaNO}_{3}$ concentration. The procedure was that in all cases the setting has started with a blanket of the electrolyte on the top of the sample. After one day the electrolyte was taken off the samples. The samples with the $1 \mathrm{M}$ and $0.2 \mathrm{M}$ concentrations were taken out of bcx after three days while samples with the $0.04 \mathrm{M}, 0.01 \mathrm{M}, 0.002 \mathrm{M}$ still set in box, after about 1 month, these samples shrunk, then were taken out of the box. Since the high concentration samples were taken out of their boxes early, cracks developed quickly, and " $\mathrm{A}$ " and the " $\mathrm{C}$ " change rapidly. In the low concentration samples, cracks developed slowly and the time evolution of the " $\mathrm{R}$ " and " $\mathrm{C}$ " was smooth. Figure 5 shows the time evolution of the resistance and capacitance of the five samples. The trends are obviously problematic with the more concentrated electrolytes showing higher resistivity than the samples with lower concentrations. After about three months all the samples cracked at the electrode insertions, highlighting the need to improve the setting conditions and to check the role of crack formation on the impedance measurements.

\section{Reproducibility}

We have started a new series of drying experiments, this time emphasizing sample-sample reproducibility. This was done to get an experimental handle over the random crack formation and its influence on the impedance measurements. We have used three electrolyte concentrations $(1,0.2$ and $0.04 \mathrm{M}$ ) and prepared five "identical" samples with each electrolyte. Some of the samples were covered with an electrolyte for one week and then were let dry and some of the samples were covered for two weeks and then were allow to dry. We did not notice any cracks in any of the samples. We show representative results for the low electrolyte concentration in Figures 6 and 7. In that case the onset approximately corresponds to the onset of the natural drying which indicates that with these low electrolyte concentration the current flows through the top electrolyte layer. The scalter with the higher electrolyte concentration is even higher. We didn't yet make a statistical analysis of the variability. It is obvious that especially with regard to the capacitance values it is very big.

Dielectric constant and resistivity

We have shown that most of our data can be represented in terms of a frequency independent $\mathrm{RC}$ elemient. The material intrinsic elements are the resistivities, $\sigma$, and the dielectric constants, $\varepsilon$, which relate to $\mathrm{R}$ and $\mathrm{C}$ through the geometric factor of the electrode configuration. The geometric factor can be evaluated by measuring the same electrolyte with a conductivity meter in which the geometric factor is known. Such an evaluation for various electrolyte concentrations was performed and over two orders of magnitude of electrolyte conductivities the cell constant was shown to be independent of concentration. If we take the high concentration electrolyte $(R=1 \Omega)$ and take $\varepsilon=80$ for water, the peak impedance should be at $10^{9} \mathrm{~Hz}$. This is two orders of magnitude above our high frequency limit. This is one of the main reasons that there is almost no literature data on measurements of the dielectric constant of aqueous solutions at audio frequencies. We have spent considerable amount of efforts in 
Irying to measure the dielectric constant of water at these frequencies. For reasons not yet fully understood we are able to get a distance independent, correci, dielectric constant of water only by using a two-electrode arrangement while the three electrode arrangements give results 2-3 times higher than expected. The fact that the dielectric constant is independent of the interelectrode separation and has an impedance spectrum well represented by a single $\mathrm{RC}$ over a broad frequency regime is a strong indication that electrode polarization is not a problem in these measurements. However this is not guarantied and we have to learn how to make these measurements in three electrode configuration. In addition, because of the limitation on resistivities, at our present frequencies we will not be able to measure the dielectric constant with the electrolytes of interest and probably will have to concentrate on conductivity measurements.

\section{Conclusions}

These results suggest that impedance measurements at the range of frequencies that was cover in this work (from $10^{-2}-10^{7} \mathrm{~Hz}$ ) do not contain more information than a single frequency conductivity measurements. These results also suggest that irreproducibilities due to random cracking is a major stumbling block for quantitative interpretation of transport properties of this medium.

\section{Electrochemical Potentials}

Techniques that are based on scanning or monitoring the electrochemical potential are at the heart of many of the electrochemical analytical techniques. They can be based either on selective oxidation / reduction of constituents in the electrolyte or in the absence of charge transfer between the electrode and the electrolyte on liquid junction potentials such as the diffusion potential. The main requirement in both cases is the incorporation of a non-polarizable reference electrode. We have tried to incorporate two kinds of reference electrodes: $\mathrm{Cu} / \mathrm{CuSO}_{4}$ which was construoted based on ASTM "Standard Test Method for Half-Cell Potentials of Uncoated Reinforcing Steel in Concrete" and the more conventional Standard Calomel Electrode. We have encountered similar reproducibility problems to the one that were described earlier in conjunction with the impedance measurements.

\section{Acknowledgement}

This work was supported by the Westinghouse Hanford Company.

\section{References}

1. See for example "The Chemistry and Physics of Composite Media", M. Tomkiewicz and P.N. Sen, eds, The Electrochemical Society (1985).

2. J. Pummersheim and J.R. Cliftor, Mater. Const., 18,21 (1985).

3. See for example: D. D. Macdonald, M. C. H. McKurbe and M. Urquidi-Macdonald, Corrosion 44, 2 (1988)

4. E.J. Garboczi and D.P. Bentz; J. Mater. Sci., 2.Z, 2083 (1992)

5. B.J. Christensen, T.O. Mason, and H.M. Jennings, J. Am. Ceram. Soc., 75, No.3(1992).

6. G.E. Archie; Trans. AIME, 146, 54 (1942).

7. See for example - Electrical Impedance Tomography; J.G. Webster editor, The Adam Hilger Series on Biomedical Engineering (1990).

8. ASTM - G 57-58

9. M.C.A. Fantini, W.M. Shen, M. Tomkiewicz, and J.F. Gambino; "Liquid Junctions for Characterization of Electronic Materials Spectroscopy of Reactive Ion Etched Si", J. Appl. Phys., 66, 2148 (1989).

10. K.B. Kim and D.R. Sadoway, J. Electrochem. Soc., 139, 1027 (1992). 


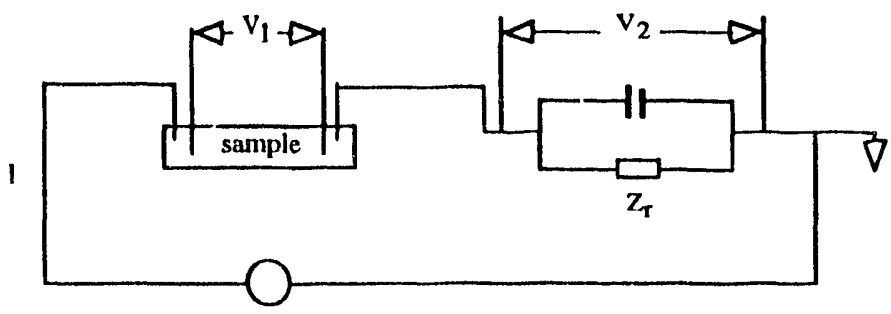

Figure 1. The measuring electrode arrangement for a four-probe system. Four electrodes are placed with equal separation in a straight line. An a.c. voltage generator is applied between the outer electrodes. $V_{1}$ is measured between the inner electrodes. $Z_{r}$ is a series resistor with a known resistance. The current flowing through the sample can be obtained from $V_{2}$. The impedance between the inner electrodes can be evaluated from $V_{1}, V_{2}$, and $Z_{r}$.

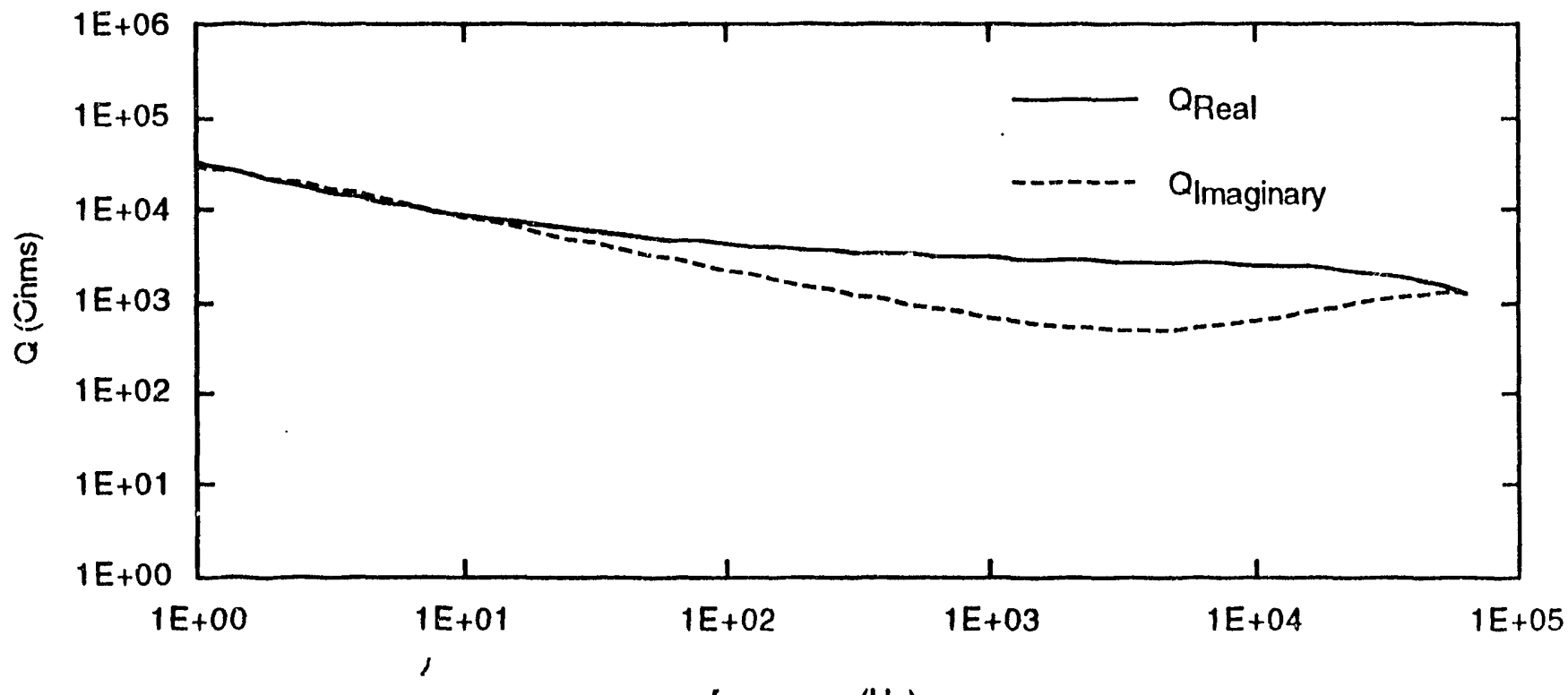

frequency $(\mathrm{Hz})$

Figure 2. The impedance spectrum of cementitious grouts made from type II Portland cement mixed with $1 \mathrm{M} \mathrm{NaNO}_{3}$ electrolyte $(\mathrm{W} / \mathrm{C}=1: 2)$ using two-probe configuration. The setting condition of the cement paste. The conditions for the cement paste setting are $48 \mathrm{hrs}$ with water covered surface at room temperature. The electrode are stainless steel wires with diameter $0.024^{n}$. The inter-electrode spacing is $4 \mathrm{~cm}$. 


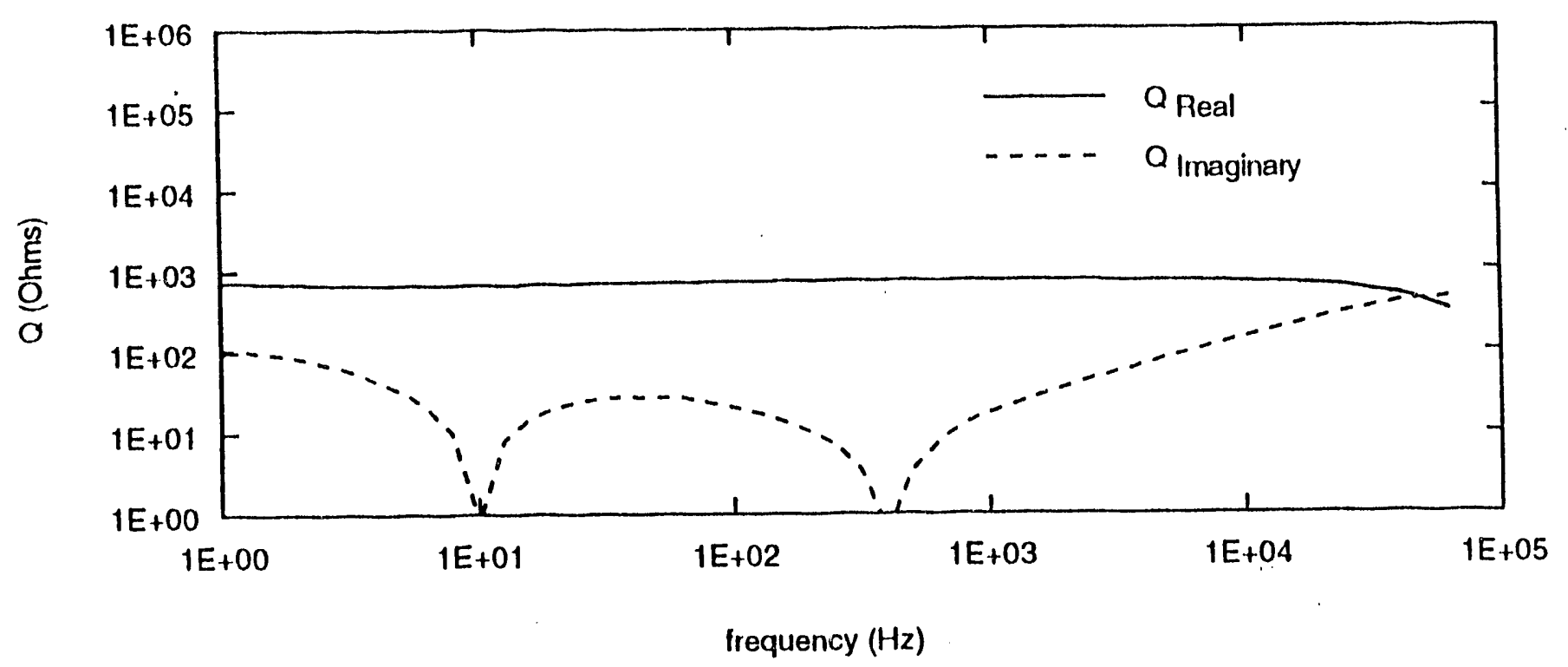

Figure 3. The impedance spectrum of cernenlitious grouts using four-probe system shown in Figure 1. The composition and setting condition of the cement sample are the same as that used in Figure 2. The electrode material and the electrode spacing are the same as that in Figure 2.

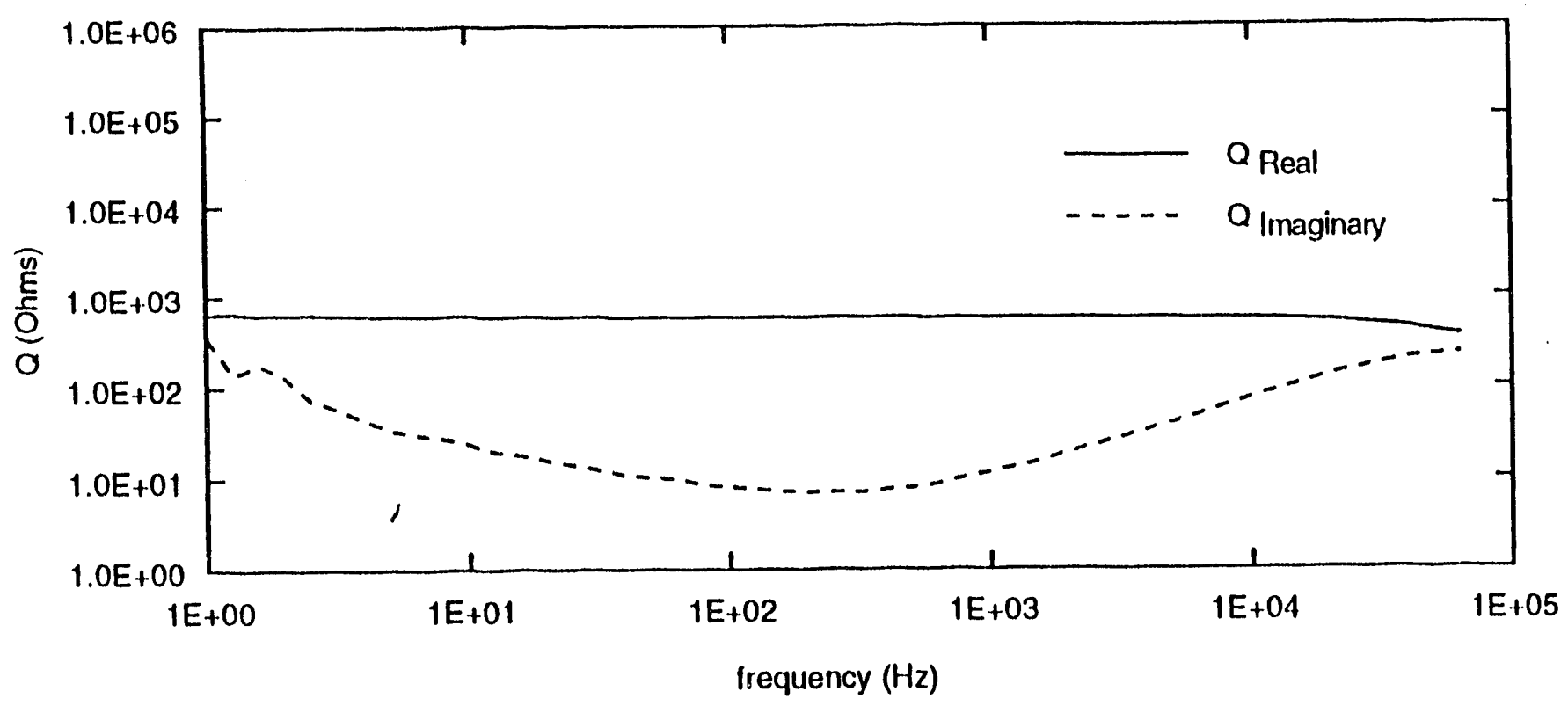

Figure 4. The impedance spectrum of cernentitious grouts using the difference between measured inpedance wilh two three-probe systems. The composition and selting condition of the cement sample are the same as that used in Figure 2. The electrode material and the electrode spacing are the same as that in Figure 2. 


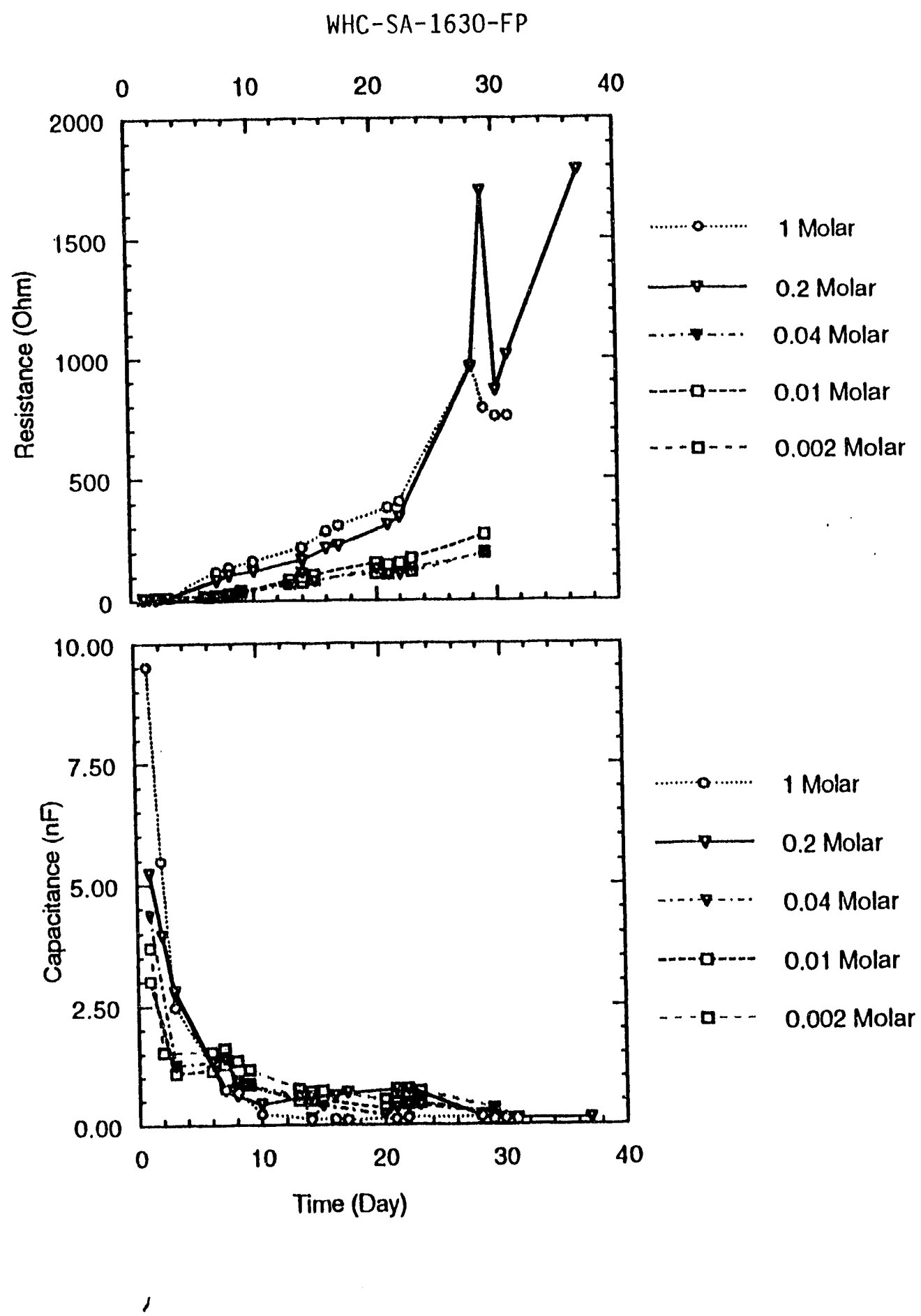

Figure 5. The time evolution of the resistance and capacilance for different electrolyte concentrations with $\mathrm{NaNO}_{3}$ and $8.4 \mathrm{Lb} / \mathrm{gal}$ of the reference dry blend. 
WHC-SA-1630-FP
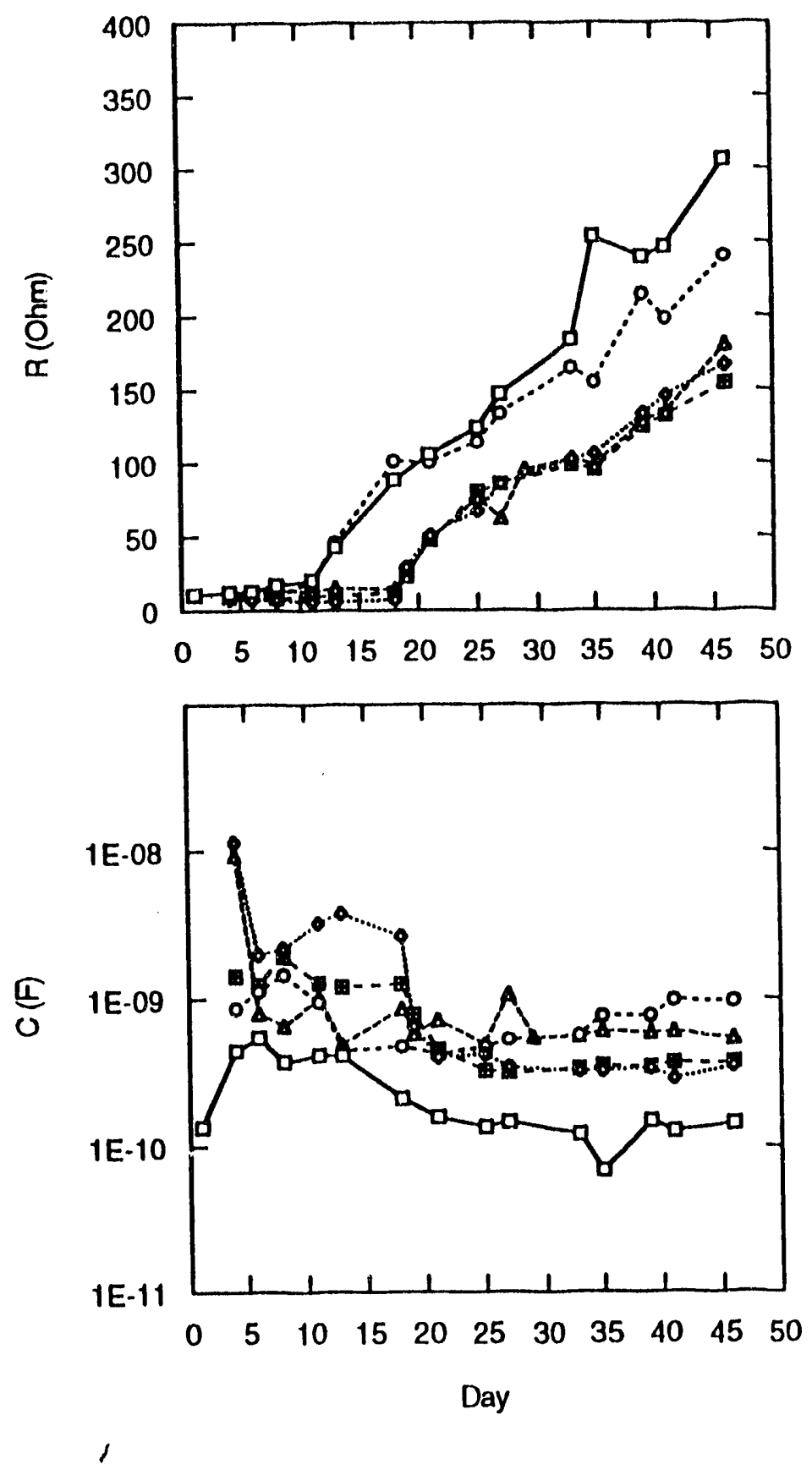

Figure 6. The time evolution of $C$ and $R$ of five "identical" samples made with similar dry blend to the one used in Figure 5. with $0.04 \mathrm{M}$ concentration of $\mathrm{NaNO}_{3}$. Two of the samples were covered for week with an electrolyte and three of the samples for two weeks. 

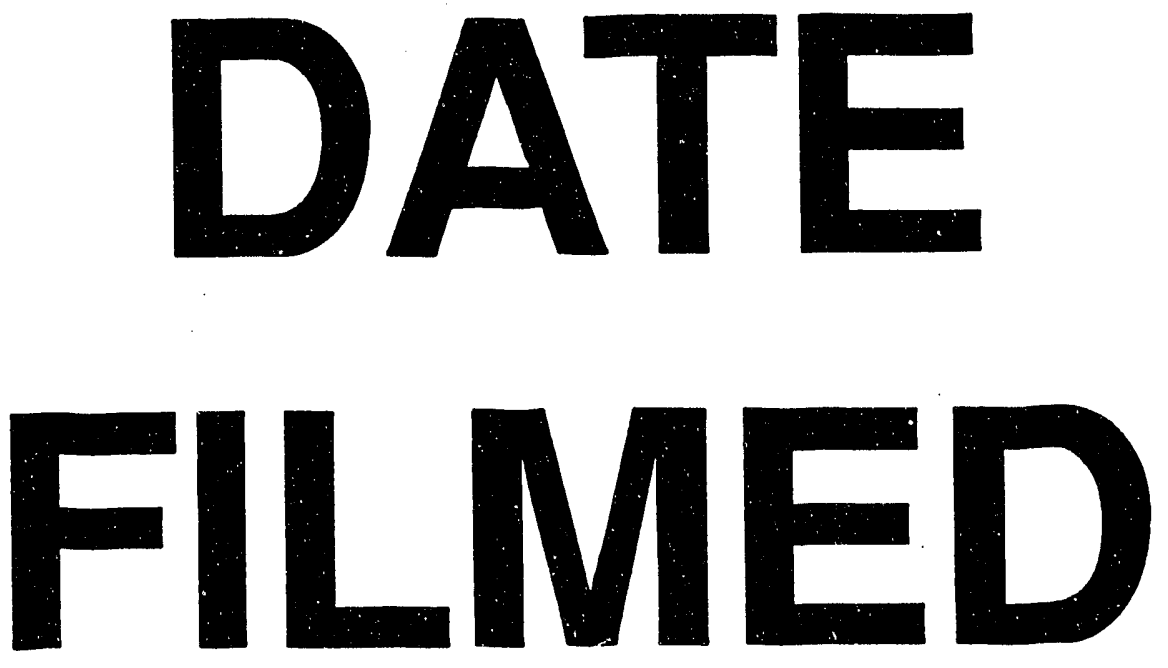

$8 / 17 / 93$
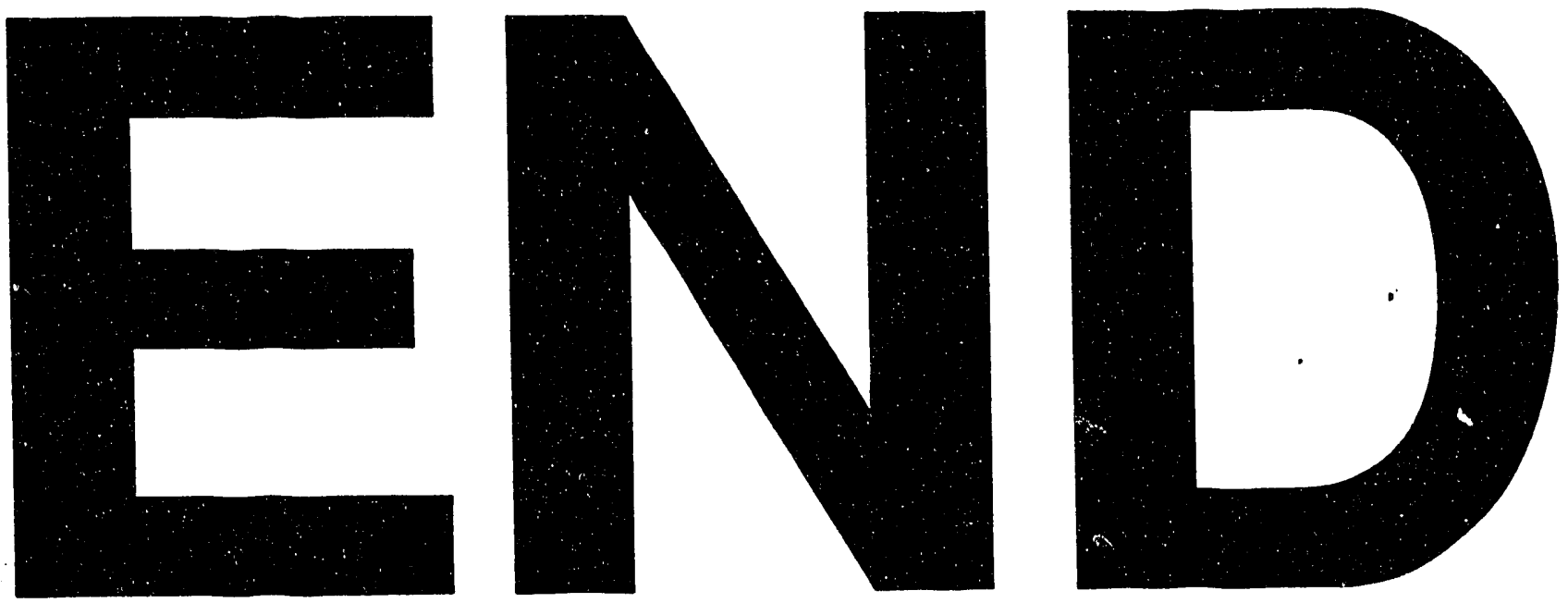